\title{
Influence of moisture on the durability of protective and decorative coatings of external walls of buildings
}

\author{
Valentina Loganina* \\ Penza State University of Architecture and Construction,, Penza, German Titov str., 28, 440028, \\ Russia
}

\begin{abstract}
The article presents the results of a study of the effect of air pressure in the pores of a cement substrate, which occurs when the wall material is moistened, on the crack resistance of protective and decorative coatings. It is shown that the value of air pressure in the pores of the material, provided that the moisture content of the wall material does not exceed the sorption limit, does not pose a threat to the integrity of most coatings. When the moisture content of concrete is higher than the sorption air pressure, it is comparable to the long-term cohesive strength of some protective and decorative coatings (lime, polymer-lime, KhSPE, etc.). When finishing external wall panels with a paint composition based on organic solvents (toluene, xylene, etc.), a saturated vapor-gas mixture is formed in the pores, which helps to reduce the rate of surface condensation. The destruction (peeling, cracking) of coatings from the action of air pressure in the pores of the substrate begins later in comparison with coatings based on aqueous paint formulations.
\end{abstract}

\section{Introduction}

One of the factors affecting the external environment on protective decorative coatings of external walls of buildings is moisture. Moistening of coatings leads to disruption of interphase bonds (hydrolysis, electrolytic dissociation, etc.), sorption softening of the coating volume and the "coating-substrate" boundary layer [1-3]. The peculiarities of the work of protective and decorative coatings of the external enclosing structures of buildings are that in the cold season, through the enclosing structure, water vapor diffuses from the inner surface to the outer [4].

In the "coating-substrate" contact zone, pores are not completely filled with a paint composition. With an increase in surface porosity, the number of such pores increases. When moisture condenses, the air in such pores is compressed and puts pressure on the paint layer, contributing to its destruction [5-7]

\footnotetext{
* Corresponding author: loganin@mail.ru
} 
Inspection results on painted building facades indicate that cracking and flaking are the most common coating defects [8-10]. These defects appear mainly in the spring. In this regard, it is relevant to study the effect of moisture on the cracking and flaking of coatings.

\section{Materials and research methods}

Polyvinyl acetatcement, lime, paints were used as paint compositions.

The air pressure in the pores was calculated in accordance with the Mendeleev Clapeyron law

$$
P V=\frac{m R T}{\mu}
$$

We assume that the pore parameters and gas mass remain constant. Let the moisture content of the material for state 1 be Wo (by volume), then the saturation coefficient of the pores $\mathrm{K}_{\text {sat }}$ is

$$
K_{\text {sat }}^{1}=\frac{W_{0}^{1}}{P}
$$

where $\mathrm{P}$ is the porosity of the material.

For 2 states, when the moisture content of the material $W_{o}^{2}$, and $W_{o}^{2}>W_{o}^{1}$

$$
K_{\text {sat }}^{2}=\frac{W_{0}^{2}}{P}
$$

The $\mathrm{K}_{\text {sat }}$ coefficient characterizes the volume of water in the pores, and $\mathrm{P}-\mathrm{K}_{\text {sat }}$ is the volume of air in the pores. Taking this into account, the air pressure in the pores for state 1 will be equal to

$$
P_{1}=\frac{m R T}{\mu\left(P-K_{\text {sat }}^{1}\right.}
$$

For 2 states

$$
P_{2}=\frac{m R T}{\mu\left(P-K_{s a t}^{2}\right.}
$$

The pressure changepis

$$
\Delta P=P_{2}-P_{1}=m R T\left(\frac{K_{\text {sat }}^{2}-K_{\text {sat }}^{1}}{\mu\left(P-K_{\text {sat }}^{2}\right)\left(P-K_{\text {sat }}^{1}\right)}(6)\right.
$$

\section{Research results}

Let us consider, as an example, the calculation of additional air pressure in the pores under non-stationary conditions of diffusion of water vapor in the outer wall made of expanded clay concrete with a density of $\rho=1000 \mathrm{~kg} / \mathrm{m}^{3}$ with an outer facing (layer of cement-sand mortar with a density of $1800 \mathrm{~kg} / \mathrm{m}^{3}$ and a thickness of $0.015 \mathrm{~m}$ ). Wall thickness $0,3 \mathrm{~m}$. The wall is painted with polyvinyl acetate (PVAC) and lime paints. The initial moisture content of the concrete corresponded to the sorption moisture content of concrete at an air humidity of $80 \%$. The calculation was performed for the conditions of Moscow. The relative humidity of the air from the inside is $60 \%$ at a temperature of $18^{\circ} \mathrm{C}$. The wall thickness is $35 \mathrm{~cm}$. The calculation of the moisture state of the wall is made taking into account the vapor 
permeability of the coatings. Let us assume that the temperature distribution in the fence during the month is constant in time. The relative humidity of the air from the inside is $60 \%$, the temperature is $18^{\circ} \mathrm{C}$. The calculation results are shown in Fig. 1.

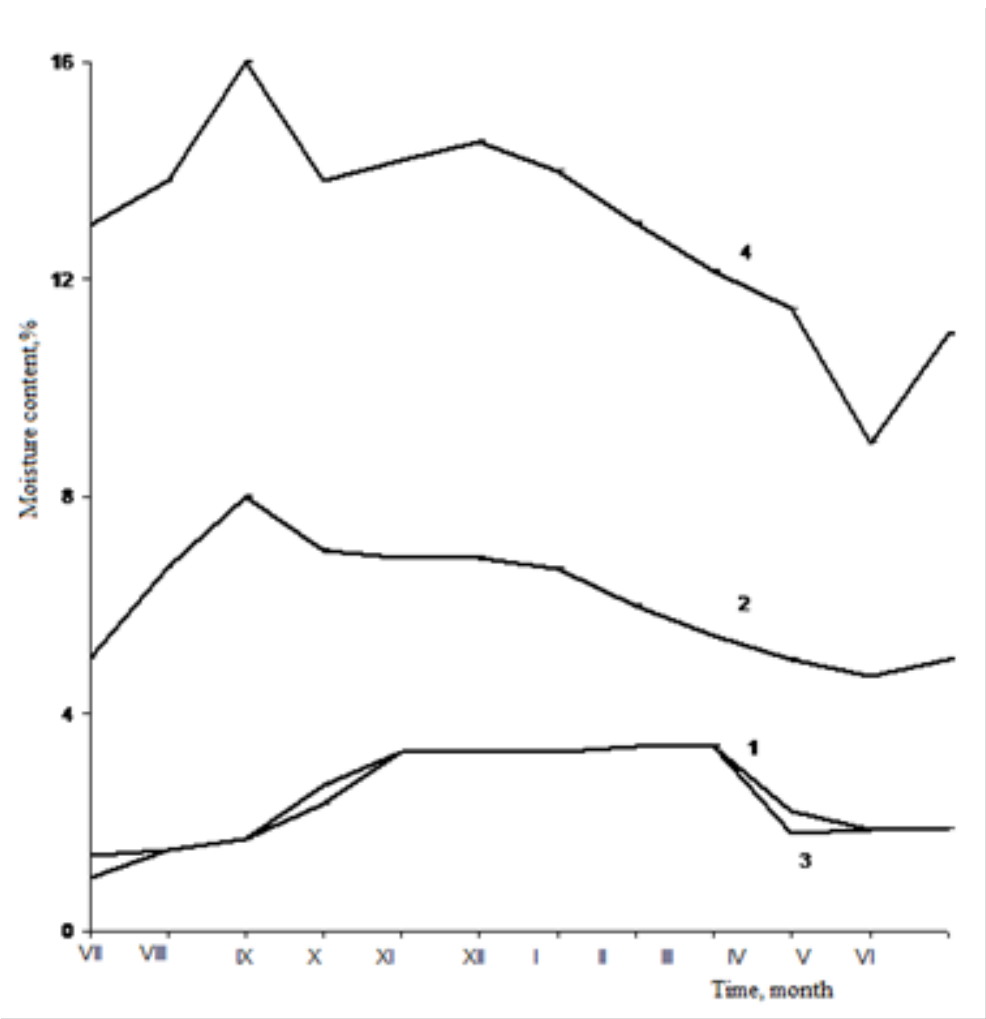

Fig. 1. Distribution of moisture content in the contact zone

1 - PVAC coating-substrate;

2 - PVAC coating;

3 - lime coating-substrate;

4 - lime coating

Analysis of the calculated data indicates that the maximum moistening of the interfacial bonds of PVAC coatings (Fig. 1, curve 1) is typical for November-March. The moisture content during this period corresponds to the maximum sorption moisture and is $3.26 \%$ for these conditions. In the period from April to July, the contact zone naturally dries out. Sorption moistening of the coating itself (curve 2) is observed in the period from August to March. The maximum moisture content is $7.4 \%$.

Similar patterns are typical for the lime coating.

Thus, the greatest probability of peeling of coatings is typical for the month of March. Increased solar radiation compared to the winter period, frequent temperature transitions through $0^{\circ} \mathrm{C}$ at the maximum moisture content of the contact layer and the coating itself contribute to the intensive destruction of the coatings.

The calculation of the air pressure in the pores of the material of the contact layer during moistening was carried out. An analysis of the experimental data (Table 1) indicates that the value of air pressure in the pores of the material, provided that the moisture content of the wall material does not exceed the sorption limit, i.e. when only water vapor diffusion is 
observed in the enclosing structure and there is no movement of moisture in the liquid phase, it does not pose a threat to the integrity of most coatings.

The air pressure does not exceed $0.112 \mathrm{MPa}$. However, the diffusion of only water vapor is observed with dried wall panels. In practice, it is often the case that panels are released from the reinforced concrete plant with a moisture content exceeding the standard. The moisture content of concrete wall panels often reaches up to $20 \%$ and drying to the standard moisture content is 4-5 years. Calculations show that with a concrete moisture content of $8 \%$, the air pressure in the pores in June reaches up to $0.214 \mathrm{MPa}$, with a moisture content of $12 \%$ - $0.244 \mathrm{MPa}$, which is comparable to the long-term cohesive strength of some protective and decorative coatings (lime, polymer-lime, etc.) ...

Table 1. The change in air pressure in the pores of the substrate in depending on material moisture

\begin{tabular}{|l|c|c|c|}
\hline Month & $\begin{array}{c}\text { Pressure P, } \\
\text { MPa }\end{array}$ & $\begin{array}{c}\text { Humidity } \\
\text { in the contact zone Wo, } \%\end{array}$ & Temperature o C \\
\hline July & 0,112 & 1,6 & 18,09 \\
August & 0,111 & 1,6 & 16,29 \\
September & 0,110 & 2 & 11,01 \\
October & 0,109 & 2,6 & 4,96 \\
November & 0.109 & 3,4 & $-1,09$ \\
December & 0,107 & 3,4 & $-6,19$ \\
January & 0,106 & 3,4 & $-8,64$ \\
February & 0,107 & 3,4 & $-8,06$ \\
March & 0,109 & 3,4 & $-3,45$ \\
April & 0,109 & 1,8 & 4,77 \\
May & 0,110 & 1,4 & 11,95 \\
June & 0,111 & 1,4 & 15,92 \\
\hline
\end{tabular}

When finishing external wall panels with a paint composition based on organic solvents (toluene, xylene, etc.), a saturated vapor-gas mixture is formed in the pores. The presence of another gas in the pore volume along with water vapor helps to reduce the rate of surface condensation. It follows from this that the destruction (peeling, cracking) of coatings from the action of air pressure in the pores of the substrate begins later in comparison with coatings based on aqueous paint compositions.

\section{Conclusion}

When the coatings are wetted, the adhesion strength decreases due to the sorption softening of the coating itself and the weakening of interphase interaction. To increase the resistance of coatings to peeling, substrates with a surface porosity of $5-7 \%$ should be used. This structure of the cement substrate is optimal from the point of view of achieving a more complete contact of the coating with the substrate.

\section{References}

1. H.M.Kunzel, , H. Kunzel, F. Holm, Protection of Stucco WTA-Schriftenreihe. 20. 117132 (1999).

2. L.X.Han, J. Han, F. M. Sun, Y. J. Huo, The Distinctive Charm of Coating-Architecture in the Modern Urban Development .Advanced Materials Research. 160-162. 880$885(2011)$ 
3. V.I.Loganina. Increasing the Durability of Paint and Varnish Coatings in Building Products and Construction. https://www.elsevier.com/books/increasing-the-durability-ofpaint-and-varnish-coatings-in-building-products-and-construction/ivanovna/978-0-12817046-5

4. L. P. Orentlicher, V. I. Loganina, Protective decorative coatings for concrete and stone buildings. Study guide (Moscow, Stroyizdat, 1992).

5. V.I.Loganina, The Influence of Surface Quality of Coatings on Their Deformation Properties. Contemporary Engineering Sciences. 7(36) 1935-194 (2014)

6. Gao Mingqiang, Ji Pengchao, Miao, Zhenyong, Pore structure evolution and fractal characteristics of Zhaotong lignite during drying. FUEL. $267 \quad 117309$ (2020)

7. A.Jenni, M.Holzer, M.Zurbriggen, M.Herwegh M , Influence of polymers on microstructure and adhesive strength of cementitious tile adhesive mortars. Cement and Concrete Research 35(1) 35-50.(2005)

8. L.A. Sukhareva, The durability of coatings, (Moscow, Chemistry, 1984)

9. M.I.Karyakina M.I.(1980). Physico-chemical basis of the formation and aging of coatings. (Moscow, Chemistry,1980)

10.V.I.Loganina, J.P. Skachkov, O.V. Tarakanov and J.G. Ivaschenko. Evaluation of the Destruction of the Coating Depending on its Thickness. Research Journal of Applied Sciences. 11: 891-893(2016) 